\title{
Effects of unemployment in mental health of young people
}

\author{
Ouzounakis Petros ${ }^{1}$, Monios Alexandros ${ }^{2}$, Vakalopoulou Marina ${ }^{3}$, Dimitriadou Alexandra ${ }^{4}$ \\ ${ }^{1}$ Medicine Department, Hospital of Alexandroupoli, Alexandroupoli, Greece \\ ${ }^{2} 7^{\text {th }}$ Secondary School of Athens, Athens, Greece \\ ${ }^{3}$ Primary Education Directorate of Evros prefecture, Alexandroupoli, Greece \\ ${ }^{4}$ Department of Nursing, Alexander Technological Educational Institute of Thessaloniki, Thessaloniki, Greece
}

\section{Email Address:}

peterouzounakis@gmail.com (P. Ouzounakis),7gymathi@sch.gr (A. Monios), marinav6@gmail.com (M. Vakalopoulou), adimitriadou@outlook.com (A. Dimitriadou)

\section{To cite this article:}

Ouzounakis Petros, Monios Alexandros, Vakalopoulou Marina, Dimitriadou Alexandra. Effects of Unemployment in Mental Health of Young People. American Journal of Nursing Science. Special Issue: Mental Health Care: Aspects, Challenges and Perspectives.

Vol. 4, No. 2-1, 2015, pp. 27-30. doi: 10.11648/j.ajns.s.2015040201.16

\begin{abstract}
Introduction: Unemployment as a problem exceeds the individual level and is the result of structural mismatches of each society. Purpose: In the present retrospective study are investigated the effects of the unemployment, especially among young people, and the prevention thereof. Material and methods: The sample consisted of recent articles on the topic, found mainly in the electronic database Medline, the Greek Academic Libraries Link (HEAL-Link) and through search engine "Google scholar". Results: The effects of the unemployment are proving disastrous for the psychology of young people, and decreases their self-esteem, they feel losing part of their social role, their relationships are made dysfunctional and eventually losing their quality of life. Conclusions: It is necessary the support for the unemployed youth of a team of experts, so that young people be enable to reevaluate their self-image and promote their quality of life.
\end{abstract}

Keywords: Unemployment, Mental Health and Mental Disease

\section{Introduction}

Work, does not provide only a person's financial rewards and his opportunity for friends and social contacts, but also plays an important role in the sense of satisfaction and selfworth of the individual. Nowadays, things in the field of employment and labor market are quite difficult, especially for young people who graduate every year from universities, "coming out" in the labor market full of dreams and hopes for the future and finally faced with the problem of unemployment [1] [2].

It is known that unemployment with the negative psychosocial consequences, affects extremely on mental health of people and social groups. Unemployment is experienced as one deleterious process uncertainty which leads to stress, guilt and low self-esteem and distorts the ensemble of social relations of the individual and the group. At the same time, unemployment suggests that there is a gap of production, a gap of consumption and an empty mood [3].

Therefore, unemployment is a severe psychosocial stressor. After all, unemployed persons, are people who would like to find a job, but they can't, either because it is not available or because an employer does not ask to them to work [2][4]. Unemployed persons have a lower confidence; feel rejected by society and in turn to developing feelings of resentment for the society. They experience years of bitterness and frustration and have symptoms of depression. Grows in them the feeling that they cannot get the life in their hands, so clipping their expectations of themselves and others [4].

In some cases, it may be expressed through psychosomatic problems or find a way to alcoholism and substance abuse, even in participating in antisocial groups and other delinquent behaviors.

\section{Aim}

The purpose of this retrospective study is to investigate the negative psychosocial consequences of experiencing unemployment, especially among young people and the prevention of them. 


\section{Material and Methods}

The sample consisted of recent articles on the topic, found mainly in the electronic database Medline, the Greek Academic Libraries Link (HEAL-Link) and through search engine "Google scholar" with keywords: unemployment, mental health and mental diseases. Exclusion criteria were the language of the articles, except articles in English and Greek.

\subsection{Effects of Unemployment in Mental Health}

Mental disorders, particularly the emotional, considered crucial for public health as they classified in the first causes who leading in significant functional impairment, and even according to the WHO expected by 2020 to become second in incidence after ischemic heart disease [5] .

The impact of unemployment on health has been the subject of many epidemiological studies. More specifically, British studies in the $70 \mathrm{~s}$ and $80 \mathrm{~s}$, showed that the mortality rate of unemployment was $25 \%$ higher than that of workers equivalent socioeconomic level [6].

A particularly interesting study made in Finland, in men and women, showed the following: Unemployment has a high correlation with mortality after or during the economic crisis in Finland in the period 1989-1994. A significant percentage of this mortality came from heart problems and suicide [7].Inaddition, cardiovascular disease is the most common cause of death in industrial countries[8].

Moreover, increased morbidity and mortality it seemed as a result after long-term unemployment when taking into consideration other factors such as age, race, marriage, income, occupation and limited access to health care [9].

The issue of the impact of the economic crisis generally and joblessness especially in mental health, concern to the scientific community and emphasize the need to provide appropriate intervention by health systems. In the Lancet journal reported that depressive disorders and the number of suicides will be increased significantly [10].

Stuckler et al. studied in 26 European countries for the period 1970-2006, the way that economic changes have affected mortality rates in Europe over the last three decades as well as the way that governments could curtail these negative effects. They found that for every $1 \%$ of increase in unemployment, there was $0.8 \%$ increase in suicides at ages under 65 , and $0.8 \%$ increase in homicides. Also, an increase of more than $3 \%$ in unemployment had respectively a greater impact on suicide (increase> 4\%), at ages 65 years and deaths caused from alcohol use [11].

Finally, another important factor associated with mental health is the use of substances; as well it seems that collates the economic crisis and drug use [12].

As regards Greece, in studies was found that mental health indicators that appeared to have a significant correlation with the economic indicators, are visits to the outpatient clinics and emergency departments of psychiatric clinics, suicides, homicides, and the number of divorces. More specifically, positive correlation was found between visits to outpatient and emergency of Aiginitio and joblessness and average income. An important finding of the research is the existence of a positive correlation of unemployment and the number of homicides [5].

\subsection{Effects of Unemployment on Mental Health of Young People}

Working for young people is necessary into societies, not only for the acquisition of livelihood, but mainly because the economic activity is considered pivotal of identity of the young person. This approach gives a more dynamic understanding and raises the issue in its proper basis. It is clear that unemployment is eminently a social phenomenon with social implications. Only in this way it becomes clear that any individual problems of unemployed young people experienced in a much more extreme way because of the structural inequalities that exist in the social system. It is therefore important to understand that unemployment is primarily a problem of society, and not only unemployed person's problem [2] [3].

The typical problems of the unemployed have an impact on their family. Particularly in cases of unemployed parents, frustration, bitterness, the sense of incapacity to maintenance their selves and their families create ambivalent feelings in the unemployed person in relation to his family, which may be expressed through constant irritability, conflict, sexual dysfunctions and vanishing trends [13] [14].Nursing interventions can be used to assist the family with their fears and concerns [15].

In Ireland over 100,000 brochures were printed on mental health in an effort to prevent suicides of people who were unemployed or facing serious financial problems due to the economic crisis. The National Office for Suicide Prevention announced that unemployment increased by $70 \%$ the risk of suicide, even in people who have no history of mental illness. In $2008,9,218$ people were transferred to hospitals because they attempted to harm themselves. Indeed, the number of people hurt themselves increased in 2008 compared to 2007. For young Irishmen, suicide is the leading cause of death. Also, an increase in demand for antidepressants observed [3] [16].

When the opportunity to test one in real working conditions is not given, then the anger is the first emotion that arises. This anger may be aptly expressed in conscious level and politically, with political mobilization and protest, since unemployment is an issue with political dimensions. This anger is healthy and respected and needs space to express aptly. Anger proceeds of depression and can be avoided when he who feels the anger could transform it in creative and responsible attitude and practice, adapted to the circumstances. Young unemployed may reflect a greater aggression toward their parents, if they feel that their parents - as representatives of the society of the adults- have betrayed or not accept them. They are demanding for them and believe that they owe to them. Others feel badly charging their parents and feel blameful because they cannot support themselves [17]. 
Should be noted that in Greece, while unemployment is increasing, young Greeks do not experience as intense the phenomenon of social exclusion in relation to to rest of unemployed Europeans, and Greeks continue to be supported financially by their families, remaining in a state of dependence on these. The family in such a situation plays an important role, both as a recipient of the emotional state and behavior of the unemployed, as well as a supportive mechanism [18]. Unemployed people, depending on their role their position within the family may feel different emotions. In this case, one remains in a stage "prolonged adolescence", which protects in true from social exclusion which can be generated by unemployment, but prevents him emotionally to become independent and take the responsibility for his life on a professional and personal level [5].

\subsection{Addressing and Preventing Opportunities}

In Greece, with unemployment rates rising every day, the researchers believe that they should be more active efforts to detect and treat mental disorders in high-risk groups. This could be done at low cost with the collaboration for example of the Manpower Employment Organization and voluntary organizations throughout Greece [9].

Also, it is important to focus on a better planning for mental health services According to a recent research of Giotaki (2012) there seems to be a negative correlation between accessibility, proximity and number of health services with the indicators of suicide [19]. The development of new management practices and the rapid modification of the organization of work policies procedures and the hierarchical structure is imperative [20].

Therefore, to overcome the destructive and suicidal tendencies in young people, created due to unemployment, basic requirement is to explore the contradictory social and psychological aspects of these trends, so as to produce a scientific analysis and approach to the problem of unemployment by group of scientists, made up of health professionals, educators, economists and political scientists [21] [22]. These could help to create support Counseling Centers of unemployed youth, aiming at their exculpation, preventing marginalization and their antisocial behavior [23] [24].

\section{Conclusions}

According to the above, the economic crisis seems to have implications on health and particularly on mental health mainly through unemployment and the reduce of income. Unemployment also exceeds the individual level and is the result of structural mismatches of social organization. The consequences of unemployment are proving disastrous for the psychology of young people, and more specifically, decreases their self-esteem, feeling that they are not creative, losing part of their social role, and their relationships become dysfunctional and eventually losing their quality of life.

So it is often necessary the support of an expert for the person, help him to re-evaluate the causes that have led to unemployment, the impact of this situation on of the selfconcept and generally in the quality of his life.

\section{References}

[1] Anonymoushttp://www.siakantari.gr/stres/anergia-psixikiygeia.html.Last visit at 12/10/ 2014.

[2] Fradelos E., Iliades Ch., Kourkouta L. (2014) Effects of unemployment on mental health. 5th National Conference of the Forum of Public Health \& Community Medicine. Thessaloniki, November 21-23.

[3] Katsoridas D., Lehouritis G. (2010)Social and psychological impact of unemployment. Encephalos, 47(4):181-188.

[4] Fatourou M. (2010) Employment and unemployment: psychological effects Encephalos, 47(4):176-180.

[5] Giotakos O., Karampelas D., KafkasáçA. (2011) Effect of the economic crisis on mental health in Greece. Psychiatry, 22:109-119.

[6] Giotakos O. (2010) Economic crisis and mental health. Psychiatry, 21(3): 195-204.

[7] Martkainen P., Maki N., Jantti M. (2007) The effect on Mortality following Workplace Closure: A Register - based Follow-up study of Finish Men and Women during Economic Boom and Recession, American Journal of Epidemiology, 165(9). The Johns Hopkins Bloomberg School of Public Health, USA.

[8] Tsaloglidou A., Rouska E., Charokopos N. (2007) The impact of exercise training on the vascular endothelium. Cardiology, 2: $117-123$.

[9] Efthimiou K., Argalia E., Kaskampa E., Makri A. (2013) Economic crisis and mental health. What do we know about the current situation in Greece? Encephalos 50, 22-30.

[10] Kentikelenis A., Karanikolos M., Papaninolas I., BasouS., McKee M., Stuckler D. (2011) Health effects of financial crisis:omens of a Greek tragedy.Lancet.378:1457-1458.

[11] Stuckler D, Basu S, Suhrcke M, Coutts A, McKee M. (2009) The public health effect of economic crises and alternative policy responses in Europe: an empirical analysis. Lancet, 374: 315-23.

[12] Ng K, Agius M, Zaman R. (2011) The Effects of the Economic Crisis On Mental Health. Eur Psych, 26:663.

[13] Leiter, M. P. (1990) The impact of family resources, control coping and skill utilization on the development of burnout: A longitudinal study. Human Relations, 43, 1067-1083.

[14] Tsitsis N, Chrysomallis M, Kourkouta L. Protection children from exploitation. Progress in Health Sciences, 2013: 3(2); $119-122$

[15] Tsaloglidou A., Rammos K., Kiriklidis K., Zourlandani A., Matziari C. (2007) Nurse's ethical decision-making role in artificial nutritional support. BJN, 16 (16):996-1001.

[16] Anonymous (20009) Suicide? Do not even think about it. Campaign to prevent suicide's wave because of the crisis in Ireland ", Newspaper "The Avgi”, 10/4/2009. 
[17] KoutsiE.(2008), Psychological Consequences of youth unemployment, Corfu's Center for Mental Health - I.K.П. http://tkaridipsynk.blogspoy.com, 21 July 2008. Last visit at $10 / 11 / 2014$

[18] Velentza O., Fradelos E., Blachothanasi E., Athanasiades E., Kourkouta $\Lambda$. (2014) The role of the nurse in the management of anxiety. 2nd National Conference of Mental Health in P.H.C. Athens, December 18-20.

[19] Giotakos O, Tsouvelas G, Kontaxakis B. (2012) Suicide and mental health services in Greece. Psychiatry, 23:29-38.

[20] Oikonomou N, Mariolis A. (2010) How is Greece conforming to Alma Ata's principles in the middle of its biggest financial crisis? Brit J Gen Pract, 456-457
[21] Kourkouta L., Papathanasiou I. V.(2014) Communication in Nursing Practice. MaterSociomed. Feb; 26(1): 66-68.

[22] Kourkouta L, Barsamidis K, Lavdaniti M. (2013) Communication skills during the clinical examination of the patients. Progress in Health Sciences, 3(1); 119-122.

[23] Tsaousoglou A., Koukourikos K. (2007) Quality and health services. Stigma, 15 (1): 18 -24.

[24] Lehouritis G, Katsoridas D. (2002) Psychosocial effects of unemployment. The deleterious process. Notes of INE, August 22-23, 105-118. 